\title{
Comparative Study of Two Commercial Photovoltaic Panels under Natural Sunlight Conditions
}

\author{
Daniel T. Cotfas $(D)$ and Petru A. Cotfas \\ Electrical Engineering and Computer Science Faculty, Transilvania University of Brasov, Romania \\ Correspondence should be addressed to Daniel T. Cotfas; dtcotfas@unitbv.ro
}

Received 21 March 2019; Revised 24 July 2019; Accepted 14 October 2019; Published 22 November 2019

Academic Editor: Giulia Grancini

Copyright (c) 2019 Daniel T. Cotfas and Petru A. Cotfas. This is an open access article distributed under the Creative Commons Attribution License, which permits unrestricted use, distribution, and reproduction in any medium, provided the original work is properly cited.

\begin{abstract}
Photovoltaic (PV) panels are used for both standalone applications and grid-connected systems. In the former case, the PV panels used vary in size, from very small, for smart solar garden lamps, to standard, in order to ensure the necessary electric energy for a house. For these cases, it is very important to choose the best solution in terms of photovoltaic cell materials. In this paper, a comparative study of two commercial photovoltaic panels, monocrystalline and amorphous silicon, is presented. The two photovoltaic panels are measured in natural conditions, during two years, in Brasov, Romania. The emphasis is placed upon the maximum power generated by the two panels, but the cost and the lifetime are also taken into consideration. The gain in average maximum power for the monocrystalline silicon panel varies from 1.9 times for low irradiance to 2.4 times higher than the one obtained from the amorphous silicon panel, during the test period. The temperature of the monocrystalline silicon panels is lower than that of the amorphous silicon panel in the majority of measurements. The degradation rate determined in two years is $1.02 \%$ for the monocrystalline silicon panel and $1.97 \%$ for the amorphous silicon panel.
\end{abstract}

\section{Introduction}

Different types of photovoltaic cells and panels were created over time in order to improve the performance, to reduce the cost and the amount of the materials used, and also to increase their application possibilities. The photovoltaic cells are classified into four groups generally referred to as generations [1]. For the first generation, the most representative is the monocrystalline silicon $(\mathrm{mSi})$ photovoltaic cell, whose theoretical efficiency limit is around 32\% [2-4]. The polycrystalline silicon ( $\mathrm{pSi}$ ), amorphous silicon ( $\mathrm{aSi}$ ), CdTe, and CIGS are the most important photovoltaic cells from the second generation $[1,2]$. The third generation is represented by the organic or polymer, dye-sensitized solar cell DSSC and multijunction photovoltaic cells $[1,5]$. "Inorganics-in-organics" is the fourth generation [5]. The photovoltaic cells obtained by incorporating the inorganic components led to the improvements of the low-cost thin film. The next generation of photovoltaic cells will be based on the new discoveries, such as nanotube and graphene, to improve the performance of the PVs [1].
The performance of different types of photovoltaic panels was largely studied [6-19]. From two to six types were taken into account in these studies. Most of them are made under natural conditions, only two being based on the simulation model $[14,19]$. Some parameters are used to study the performance of the PV panels, namely, $P_{\max }$ (maximum power), MAE (mean array efficiencies), CF (capacity factors), and PR (performance ratio) (International Electrotechnical Commission Standard IEC-61724 [20]) [21-24].

The performance of the photovoltaic panels, such as monocrystalline, polycrystalline, and amorphous silicon, cadmium tellurium, copper-indium-diselenide, and copperindium-gallium-selenide, is studied for a location, a region, or a country. Carr and Pryor made a study for five different photovoltaic panels, among which are crystalline silicon and aSi, at Perth, Western Australia. The efficiency of the laser-grooved buried contact crystalline Si module varies between $11.5 \%$ and $12.5 \%$ on one year, and for triple junction, it is almost half [6]. Bashir et al. studied three types of photovoltaic panels in Taxila, Pakistan for winter months taking into account the efficiency and the performance ratio. 
The average efficiency of the monocrystalline panel was almost 2.3 times higher than that of the amorphous panel, while the average performance ratio of aSi is almost 1.3 times better than of the monocrystalline panel [7]. Dolara et al. studied mono and polycrystalline panels in Milano to achieve a forecast model for the power generated by panel function of weather [8]. The parameters and the degradation of crystalline photovoltaic panels using the I-V characteristics are studied for Adrar, from the southern part of Algeria [10]. The performance of different photovoltaic panels is studied for different climates, such as Mediterranean climate (Malaga, Spain), temperate mountain climate (Brasov, Romania) [13], milder climate with long winter (Grimstad, Norway) [15], and semiarid climate (Amman, Jordan) [16]. Ito et al. studied six different types of photovoltaic panels from the life cycle analysis in Hokuto, Japan [17]. Amin et al. achieved a comparative study for different photovoltaic panels under Malaysian weather [9]. Dias et al. analyzed the models to estimate PV energy and proposed a new one based on results obtained from six types of photovoltaic panels among which are amorphous silicon and monocrystalline silicon in Brazil [14]. Six photovoltaic subsystems located in Madrid were analyzed based on the performance and the degradation rate. They find out that the $\mathrm{CdTe} / \mathrm{CdS}$ technology has $2 \%$ in the first two years while the monocrystalline technology has the lowest rate [25]. Komoni et al. analyzed the performance of two panels, mono and polycrystalline connected on a grid, and obtained that the monocrystalline panel has a higher performance which generated $1328.21 \mathrm{kWh} / \mathrm{kWp}$ compared with $1286.57 \mathrm{kWh} / \mathrm{kWp}$ generated from polycrystalline panels [26]. The monocrystalline, polycrystalline, and amorphous silicon panels were tested in Casablanca, Morocco, and the results show that the monocrystalline panel has the best efficiency in both types of day, clear and cloudy [27]. Kumar et al. analyzed through simulation the performance of the three photovoltaic panels integrated in the buildings and obtained that CdTe is the best technology [28]. Ameur et al. studied three grid-connected photovoltaic technologies (monocrystalline, polycrystalline, and amorphous silicon) in the region of Ifrane, Morocco. They found out that the monocrystalline silicon and the polycrystalline silicon have almost the same performance during 51 months and the amorphous silicon has the lowest performance [29].

Although researchers developed many types of photovoltaic cells, the crystalline photovoltaic cells dominate the market and there is a trend of steady growth. Therefore, the market share is around 93\% [30]. The amorphous silicon photovoltaic cell is another major component of the silicon family, with a market share around $50 \%$ from all thin-film photovoltaic cells until 2011 [31], afterwards decreasing, CdTe thus becoming leader [32], but the aSi photovoltaic cells remain the most widely used in small applications.

Considering the aspects mentioned above, this comparative study is focused upon two of the most commonly used photovoltaic panels from their group: monocrystalline and amorphous silicon. The previous aforementioned studies are focused on medium and large applications, while the tar-

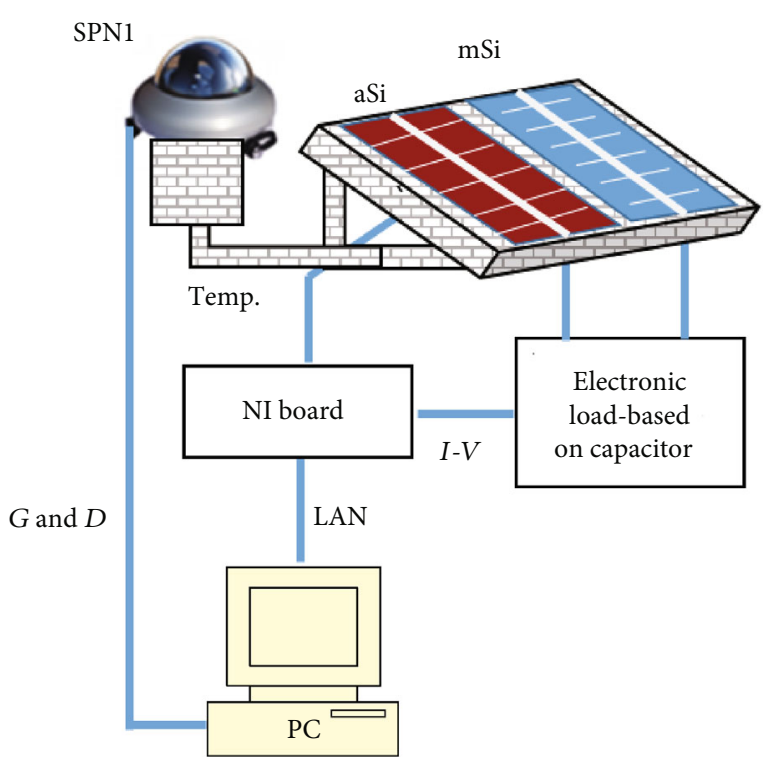

Figure 1: System setup with the two commercial photovoltaic panels.

get of this study is their utilization for standalone small applications, such as smart solar garden lamps, and by extrapolation for home photovoltaic systems. Moreover, in all studies mentioned before the photovoltaic panels had the backside free, not covered as in this study. The performance of the two photovoltaic panels is studied during two years in Brasov, Romania, at latitude $45.655^{\circ} \mathrm{N}$ and longitude $25.597^{\circ} \mathrm{E}$. The measurements were made in outdoor conditions, taking into account the temperature of the panels and the solar radiation.

\section{The Experimental Setup}

The space for photovoltaic panel in small applications is limited, and its working conditions can be different in comparison with normal PV power plants. For smart solar garden lamps, the area of the photovoltaic panels has to be as small as possible. Therefore, it is important for comparison that the PV panels have the same area. The two photovoltaic panels under testing were chosen to have the sizes of $10 \mathrm{~cm} \times 10 \mathrm{~cm}$, which can be suitable for small applications.

The two PV panels, monocrystalline and amorphous silicon, were mounted on the same support tilted at $55^{\circ}$.

The solar radiation is measured using the SPN1 pyranometer. SPN1 measured the global solar radiation $(G)$, and the diffuse solar radiation $(D)$ is calculated. This information is very useful for determining the days or the period when the sky is cloudy. The standard uncertainty for the global radiation is $0.35 \mathrm{~W} / \mathrm{m}^{2}$.

The schema of the experimental setup is presented in Figure 1 .

The current-voltage characteristics, $I-V$, of monocrystalline and amorphous silicon panels are measured using the capacitor technique [33].

The electronic load based on the capacitor technique is developed in our laboratory and permits the measurement 
TABLE 1: The month optimum angle for Brasov and the month average irradiance at optimum angles $35^{\circ}, 44^{\circ}, 55^{\circ}$, and $64^{\circ}$.

\begin{tabular}{|c|c|c|c|c|c|c|c|c|c|c|c|c|}
\hline Month & Jan & Feb & Mar & Apr & May & Jun & Jul & Aug & Sep & Oct & Nov & Dec \\
\hline Opt. tilt $\left({ }^{\circ}\right)$ & 63 & 55 & 44 & 29 & 16 & 9 & 13 & 25 & 40 & 55 & 64 & 65 \\
\hline$G_{\text {opt }}\left(\mathrm{Wh} / \mathrm{m}^{2} /\right.$ day $)$ & 1910 & 2550 & 4070 & 4570 & 4970 & 5100 & 5480 & 5260 & 4310 & 3830 & 2600 & 1640 \\
\hline$G_{[44]}\left(\mathrm{Wh} / \mathrm{m}^{2} /\right.$ day $)$ & 2010 & 2630 & 4100 & 4470 & 4760 & 4830 & 5220 & 5110 & 4320 & 3960 & 2760 & 1730 \\
\hline$G_{[55]}\left(\mathrm{Wh} / \mathrm{m}^{2} /\right.$ day $)$ & 2090 & 2660 & 4040 & 4250 & 4390 & 4390 & 4770 & 4800 & 4210 & 4020 & 2870 & 1800 \\
\hline$G_{[63]}\left(\mathrm{Wh} / \mathrm{m}^{2} /\right.$ day $)$ & 2100 & 2640 & 3900 & 3980 & 4010 & 3950 & 4320 & 4450 & 4030 & 3970 & 2890 & 1820 \\
\hline
\end{tabular}

of the $I-V$ characteristics in the same time, using the data acquisition board from National Instruments. The voltage is measured with $0.1 \mathrm{mV}$ standard uncertainty and the current with $0.08 \mathrm{~mA}$ standard uncertainty. The temperature of the photovoltaic panels is measured using two sensors, LM 35 (the typical accuracy is $\pm 0.4^{\circ} \mathrm{C}$ ), which are mounted on the back of each PV panel. The solar radiation is measured simultaneously with the $I-V$ characteristics of the photovoltaic panels. The program to perform the measurement and the control is realized in the LabVIEW software. The $I-V$ characteristics of the photovoltaic panels, the temperatures, and the solar radiation are measured at five minutes each. The data is saved, and using a suitable program developed by the authors, it is processed in order to perform the comparison.

\section{Theoretical Considerations}

The maximum power $\left(P_{\max }\right)$ generated by the photovoltaic panels is the most important parameter to perform the comparison between the PV panels, in cases of small applications. The maximum power is determined using the power voltage characteristic, $P-V$, of the photovoltaic panels obtained from the $I-V$ characteristic. The one-diode mathematical model, which is used to analyze the I-V characteristic, is described in [34]

$$
I=I_{\mathrm{ph}}-I_{\mathrm{o}}\left(e^{V+I R_{\mathrm{s}} / n V_{T}}-1\right)-\frac{V+I R_{\mathrm{s}}}{R_{\mathrm{sh}}},
$$

where $I_{\mathrm{sc}}$ is the short circuit current, $I_{\mathrm{o}}$ is the reverse saturation current, $q$ represents the elementary charge, $n$ is the ideality factor of diode, $k$ is the Boltzmann constant, $T$ is the panels' temperature, $R_{\mathrm{s}}$ represents the series resistance, and $R_{\text {sh }}$ represents the shunt resistance.

Another parameter used for comparison is the efficiency of the photovoltaic panels and it is calculated using

$$
\eta=\frac{P_{\max }}{A \times I_{s}}
$$

where $P_{\max }$ is the maximum power, $A$ represents the area of the photovoltaic panels, and $I_{\mathrm{s}}$ is the solar irradiance.

\section{Results and Discussion}

The measurements of the two photovoltaic panels are performed on the roof of the Transilvania University of Brasov throughout a two-year duration.

The goal of the PV power plants is to maximize the energy amount for the entire year, but for the PV panel used in smart solar garden lamps, the goal is to assure the energy so that the lamps work uninterruptedly for the entire year, even when there are periods without sun.

The tilt angle for the PV panel in the case of the smart solar garden lamp was chosen, analyzing the data obtained using the free PVGIS software and the Climate-SAF PVGIS database [35], see Table 1. So, the PV panel inclination was chosen, $55^{\circ}$, to maximize the amount of energy in the months when the ratio between the energy needed and the generated energy is critical taking into account the purpose of this study. The critical months are from October to February. In this period, the night is longer than the day, and the period when the smart lamp is turned on is higher than for the rest of year. For the other months, the energy generated by the photovoltaic panels is generally over the needed energy. There are other considerations for the use of tilted PV panels, such as increase in the quantity of the solar radiation falling on PV panels through reflections especially during winter (the worst period from the energy point of view) when the albedo of the fresh snow is around $90 \%$ and the self-cleaner process is improved at this tilt.

A simple way to compare the performance of the PV panels is to take into account the maximum power of the two photovoltaic panels given by manufacturers, who performed the measurements in standard test conditions (STC): irradiance $1000 \mathrm{~W} / \mathrm{m}^{2}$, air mass 1.5 , and temperature $25^{\circ} \mathrm{C}$. These conditions are rarely encountered in natural environment, and it is better to perform the comparison using the values obtained for the PV panels under natural sunlight illumination.

The maximum power generated by the PV panels and consequently their efficiency are considered for comparison because the area of the photovoltaic panels is limited and equal for the two PV panels taken into account. The maximum power and the efficiency are function of irradiance and time.

First of all, the two photovoltaic panels were measured under natural sunlight at different tilt angles on the N-S axis from 0 to 90 degrees and the azimuth angle is taken 0 degree to determine the angle effect. The horizontal solar radiation during measurements was $550 \pm 5 \mathrm{~W} / \mathrm{m}^{2}$. The measurements 


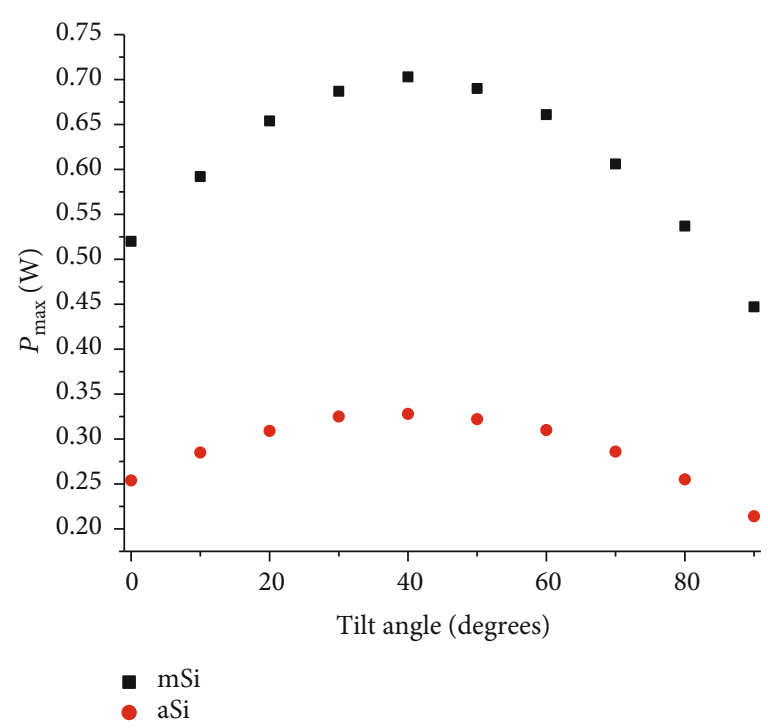

(a)

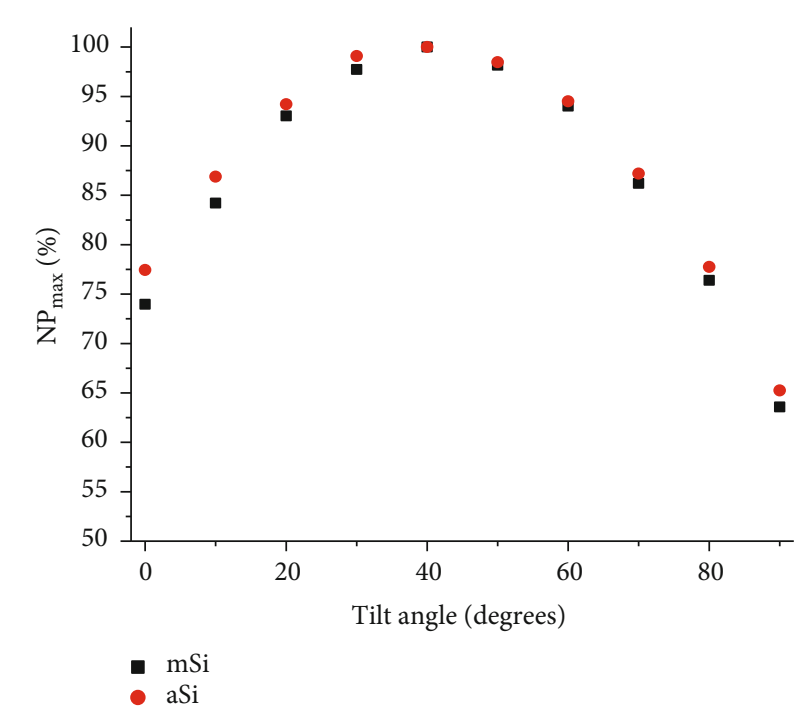

(b)

FIgURe 2: Performance comparison of the PV panels vs. tilt angle: (a) the maximum power and (b) the normalized power.

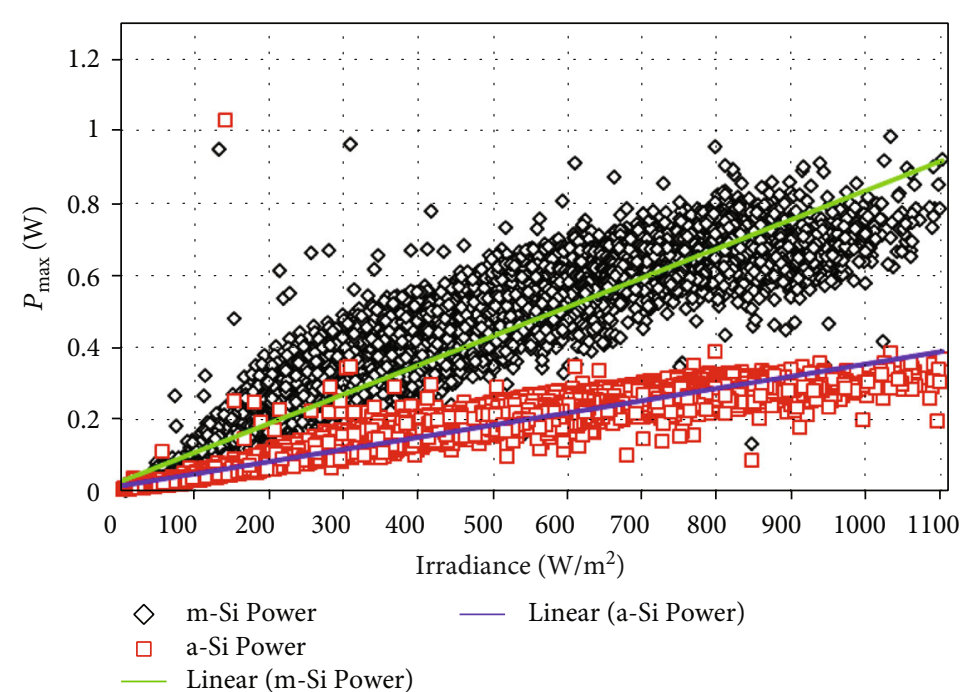

(a)

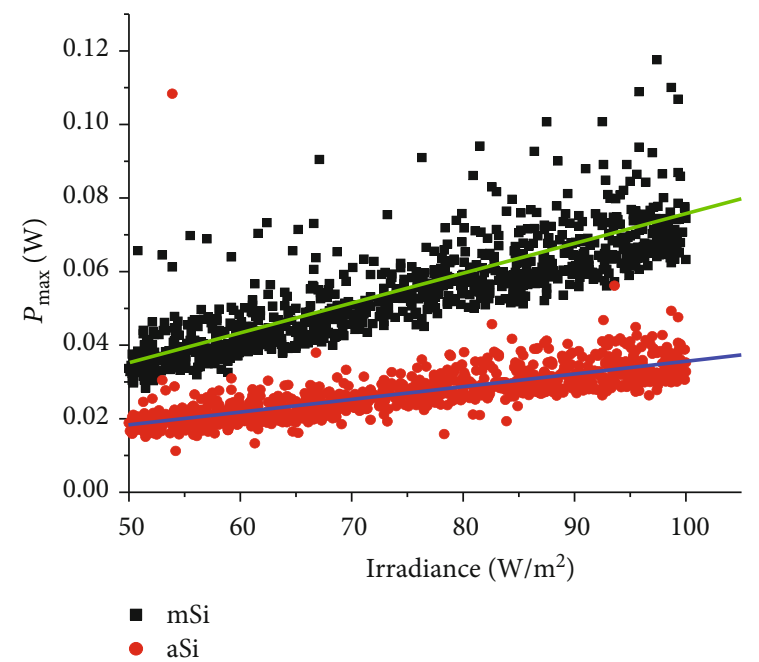

(b)

Figure 3: The maximum power of the two PV panels. (a) Irradiance from 0 to $1100 \mathrm{~W} / \mathrm{m}^{2}$. (b) Irradiance from 50 to $100 \mathrm{~W} / \mathrm{m}^{2}$.

were performed using a sun tracker, in September when for Brasov the optimum mathematical tilt angle is 40 degrees, see Table 1 . The sun tracker system consists of a tripod and a pan/tilt device J-PT-1008-D which can work with an $8 \mathrm{~kg}$ load and move the panels on two axis. The pan/tilt device is controlled using the NI myRIO device, and two encoders are used for feedback. The sun is followed using the mathematical algorithm.

The maximum power generated by the two photovoltaic panels is presented in Figure 2(a) and the normalized power $\left(\mathrm{NP}_{\max }\right)$ in Figure 2(b), being calculated as the ratio between $P_{\max }$ obtained for different angles and $P_{\max }$ at $40^{\circ}$.

The maximum value for $P_{\max }$ is obtained at 40 degrees for both photovoltaic panels which correspond to the optimum angle for September in Brasov. The maximum power gene- rated by the monocrystalline silicon panel is over two times higher than the maximum power generated by the aSi photovoltaic panel, from 2.04 at $0^{\circ}$ to 2.14 at $40^{\circ}$. The normalized power of the aSi panel is slightly bigger than that of the monocrystalline silicon panel, Figure 2(b), proving that the aSi panel has better performance in $\mathrm{NP}_{\max }$ for small values of the solar radiation, but in our case, this is less important because the monocrystalline silicon $(\mathrm{mSi})$ panel generates power around two times higher than aSi even for small values of solar radiation.

The distribution of the maximum power generated by the two photovoltaic panels, tilted at $55^{\circ}$, on two years' duration function of the irradiance is presented in Figure 3(a). The temperature correction for maximum power is not taken into account to have the real behaviour of the two 


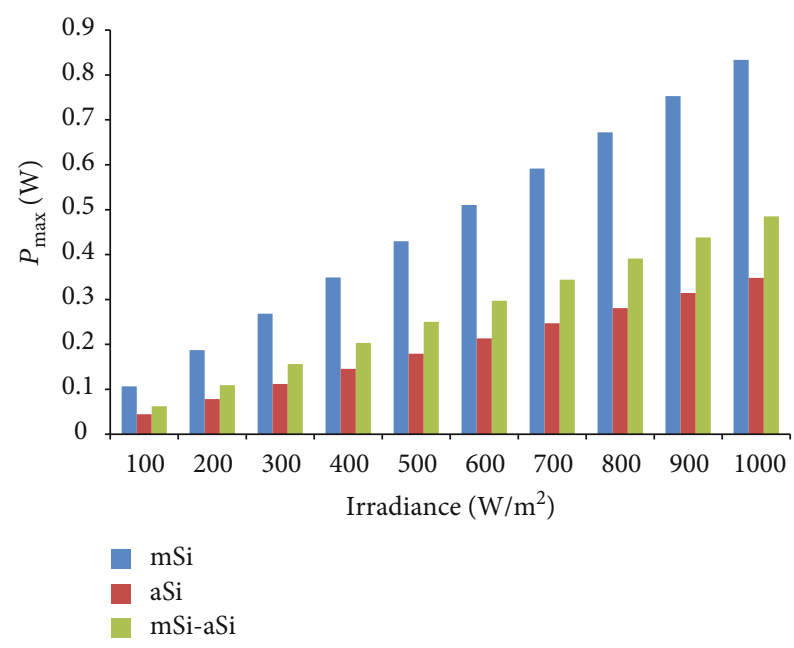

FIGURE 4: The average maximum power vs. illumination levels.

photovoltaic panels over the two years of measurement. An almost linear distribution of the maximum power function of the irradiance can be observed. The slope of the linear fit for the monocrystalline silicon panel maximum power is bigger than the one for aSi, meaning that the gain in maximum power for $\mathrm{mSi}$ increases for high values of irradiance. Figure 3(b) shows the distribution of the PV maximum power for small irradiance from 50 to $100 \mathrm{~W} / \mathrm{m}^{2}$. The monocrystalline silicon PV panel generates $35.24 \mathrm{~mW}$ at $50 \mathrm{~W} / \mathrm{m}^{2}$ while the aSi generates $18.34 \mathrm{~mW}$. These values are obtained using the linear fit equation for the two PV panels. The monocrystalline silicon panel gain in power is almost two times larger than that for aSi.

The better performance of the monocrystalline silicon photovoltaic panel in comparison with the amorphous silicon panel is due to its efficiency. The high efficiency is obtained because the technology is very well developed and the highest quality silicon is used, the purity is $99.9999 \%$. The monocrystalline silicon cell has the photoactive absorber stable, but an indirect energy band gap. This can be overpassed using surface texturing, suitable antireflection coating, and effective surface passivation.

The dependency of the maximum power average generated by the two photovoltaic panels on the irradiance is considered to have a better image (Figure 4). The difference between the average maximum power generated by the monocrystalline silicon panel and the aSi panel is also presented in Figure 4.

The values of the difference are higher than the values of the aSi maximum power for all irradiance values considered. By analyzing the results for the average maximum power function of the illumination levels, a gain is observed for the $\mathrm{mSi}$ panel which varies from 2.4 times at $1000 \mathrm{~W} / \mathrm{m}^{2}$ to 2.393 times at $100 \mathrm{~W} / \mathrm{m}^{2}$. The same behaviour is observed when the measurements were made only in a clear sky day (Figure 2(a)). The difference in maximum power is under two times for irradiance under $100 \mathrm{~W} / \mathrm{m}^{2}$ because the amorphous photovoltaic panel has good light absorbing characteristics in low irradiance. This result is in concordance with the one found by Bashir et al. [7].
In the following, analysis is made for day types in order to obtain data for specific conditions. Therefore, two days, one clear and one cloudy, were considered in winter and in summer. Figure 5 shows the maximum power variation for the four days: 6 January 2014 (Figure 5(a)), 9 January 2014 (Figure 5(b)), 3 August 2015 (Figure 5(c)), and 22 August 2015 (Figure 5(d)).

The shape of the curves for the maximum power generated by both photovoltaic panels for each of the considered days is almost the same.

The difference between the maximum powers of the two PV panels is higher for high values of irradiance. The power difference is higher in clear days than in cloudy days. The maximum power generated by the monocrystalline silicon panel can be almost three times higher than that generated by the aSi panel in clear days especially in winter, when the temperature of the monocrystalline silicon cells is smaller than the temperature of the aSi cells. This is an advantage for $\mathrm{mSi}$ because its maximum power temperature coefficient is $-0.47 \%$ and for aSi it is $-0.18 \%$ [36], and the gain in maximum power generated by monocrystalline silicon cells increases with the maximum power generated by aSi. The aSi panel is less sensitive at temperature variation than the monocrystalline silicon panel.

There are small deviations for some points which could appear due to measurement conditions which are detailed below. The difference in gain for the same type of days can be explained due to the temperature variation in the photovoltaic panels especially for cloudy days when the influence of the spectrum is high. The two panels respond differently both in temperature (see above the temperature coefficients) and spectrum. The spectral response for monocrystalline silicon cells is between $350 \mathrm{~nm}$ and $1200 \mathrm{~nm}$ with a maximum response for around $1100 \mathrm{~nm}$, and for amorphous silicon cells, it is between $300 \mathrm{~nm}$ and $800 \mathrm{~nm}$ with a maximum response for around $500 \mathrm{~nm}$. The part of solar spectrum is influenced by the clouds and the atmospheric conditions. Song et al. show that the relative decrease of the solar radiation on cloudy days is higher for wavelengths over $800 \mathrm{~nm}$ where decreasing is more than $70 \%$, whereas below this wavelength value it is smaller than $50 \%$ [37]. This explains the better behaviour for the aSi panel in cloudy days when the gain of the monocrystalline silicon panel is smaller than for clear days.

Taking into account the amplitude of the gain, even on cloudy days where this is almost two times higher, it is clear that the mSi panels are the best choice in case the area is the same for both PV panels.

The solar global and diffuse radiation for the four days are shown in Figure 6. By analyzing these graphs together with the data for the maximum power generated by the PV panels, the same behaviour for radiation and power can be observed.

The solar diffuse radiation is almost equal with the solar global radiation, as can be seen in Figures 6(b) and 6(d), for the entire day, proving that the sky was cloudy on these days.

The variation of the photovoltaic panel temperature is presented in Figure 7(a) for a winter day (6 January 2014) and Figure 7(b) for a summer day (3 August 2015). The 


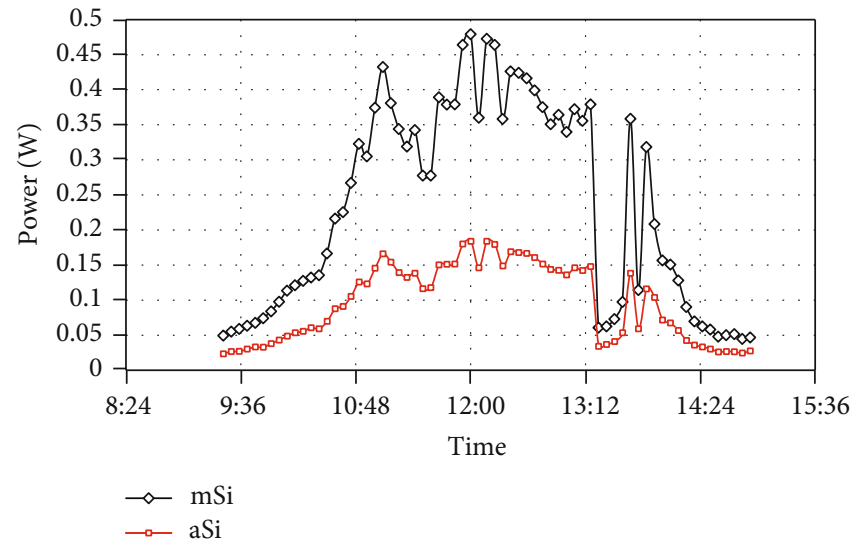

(a)

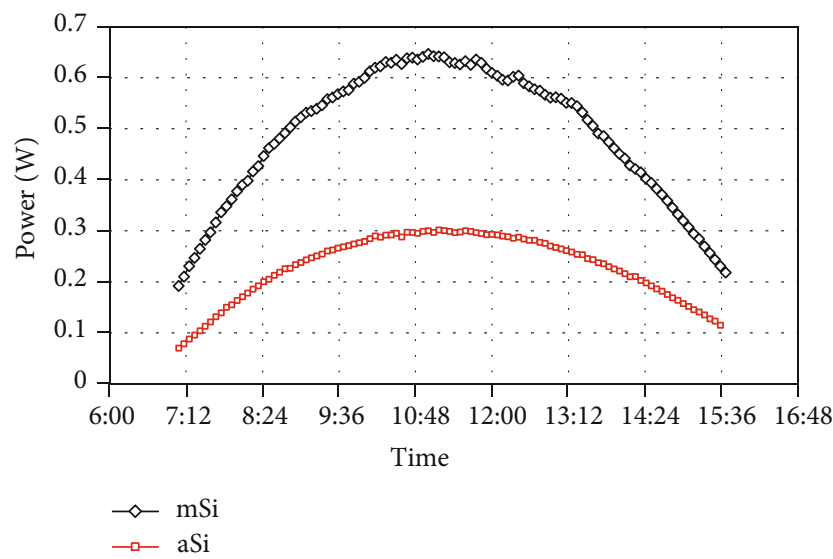

(c)

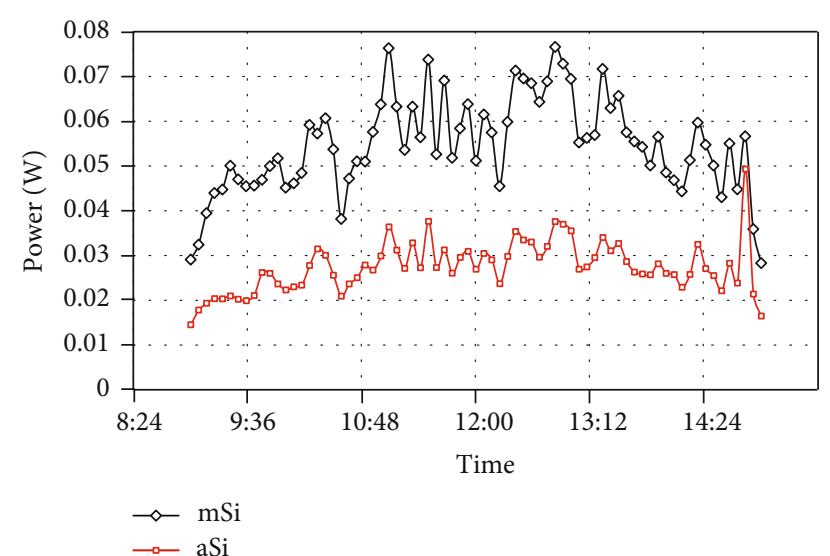

(b)

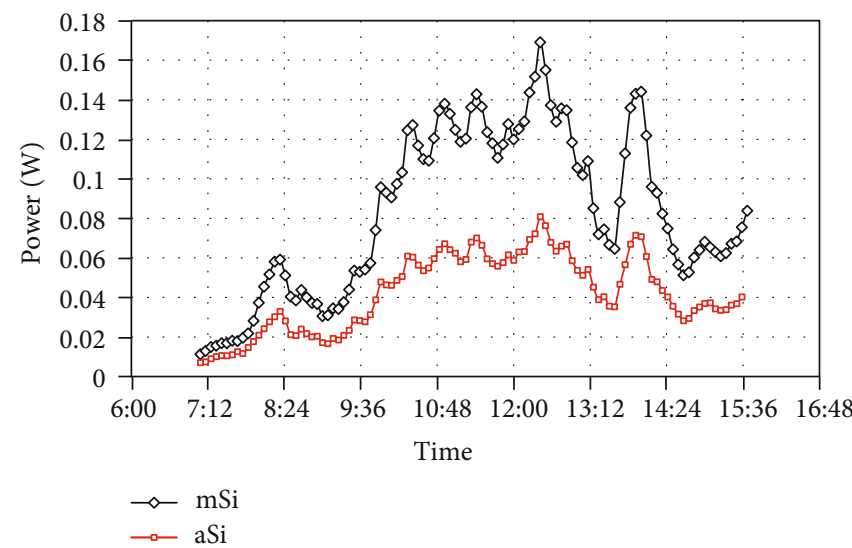

(d)

FIGURE 5: The maximum power generated by the two PV panels: (a) winter clear day, (b) winter cloudy day, (c) summer clear day, and (d) summer cloudy day.

temperature of the aSi panel in both cases is a little higher than the temperature of the monocrystalline silicon panel.

In general, the photovoltaic panels used for small applications do not have a free backside. For solar garden lamps, they have on the back the electronic circuit and the support for the light source.

The two photovoltaic panels analyzed have in the back a wooden support which is a thermal insulator to simulate the real work conditions.

The temperature difference between the two photovoltaic panels appears due to the better efficiency of the monocrystalline silicon panel, which is two times higher than the one of the aSi panel, the area of the two PV panels being the same and the PV back being covered. So, the heat dissipation effect is reduced compared to the case of PV panels for large applications, when the back of PV panels is free and the area of the aSi panel is almost two times bigger than the area of the mSi panel [7]. In the last case, the heat convection between the air and panel surface is better than that for the case under study. The higher temperature of the aSi panel is compensated by the lower power temperature coefficient $[24,36]$.

The behaviour of the efficiency for the two photovoltaic panels is the same as the maximum power because the areas of the PV panels are equal and the irradiance is the same. The average efficiency for the minimum and maximum irradiance is presented in Table 2. There are significant differences from the STC efficiency, in accordance with other studies [9]. The efficiency calculated in natural conditions is influenced by the temperature of the photovoltaic panels, humidity, spectrum of sunlight, and also dust and dirt, as PV panels are naturally cleaned.

Using the current-voltage characteristics measured, in the future work, the parameters for both photovoltaic panels can be determined. They can be compared in function of the solar irradiance and the temperature. Also, other photovoltaic panels are going to be measured and compared. The behaviour of the photovoltaic panels when they are covered with dust and snow will be taken into account in a future study.

The comparison between the two photovoltaic panels is incomplete without taking into consideration the lifetime and the cost. For mSi photovoltaic systems, it is known that after 10 years the power generated represents $92 \%$ from the initial state and after 25 years the power is $82.5 \%$. By analyzing the research literature for the lifetime behaviour of the two types of photovoltaic panels, the median degradation rate found is $0.36 \%$ /year for the monocrystalline silicon 


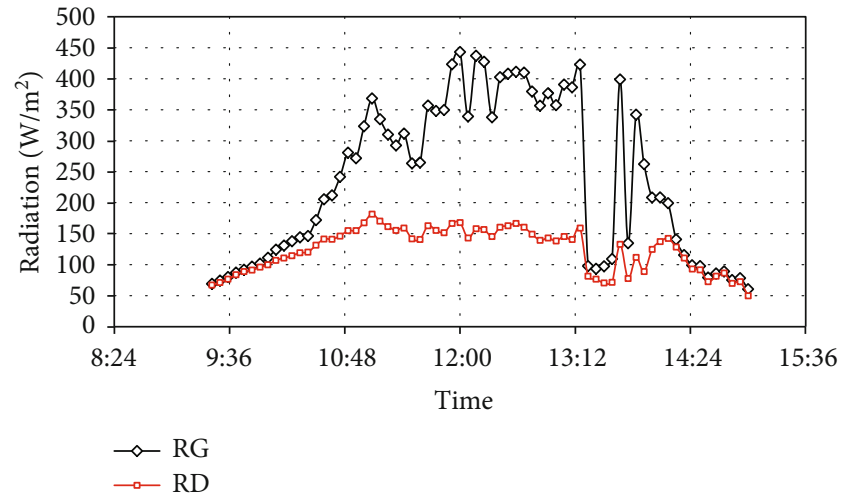

(a)

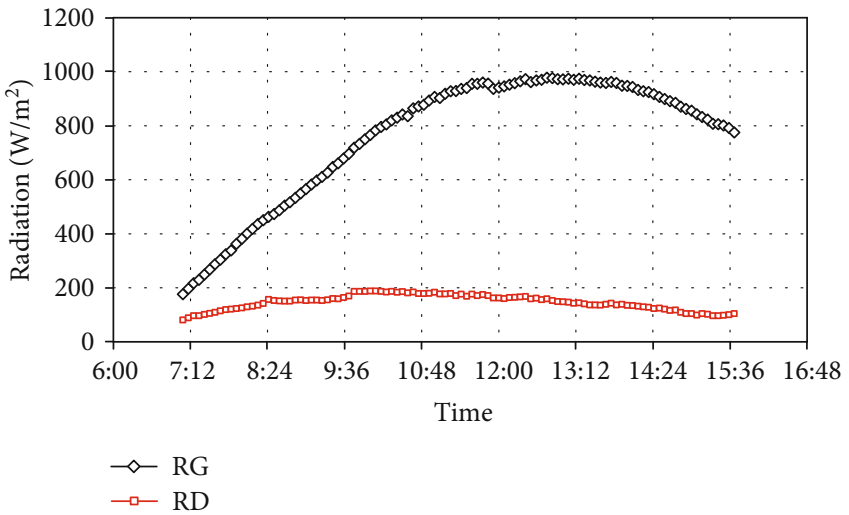

(c)

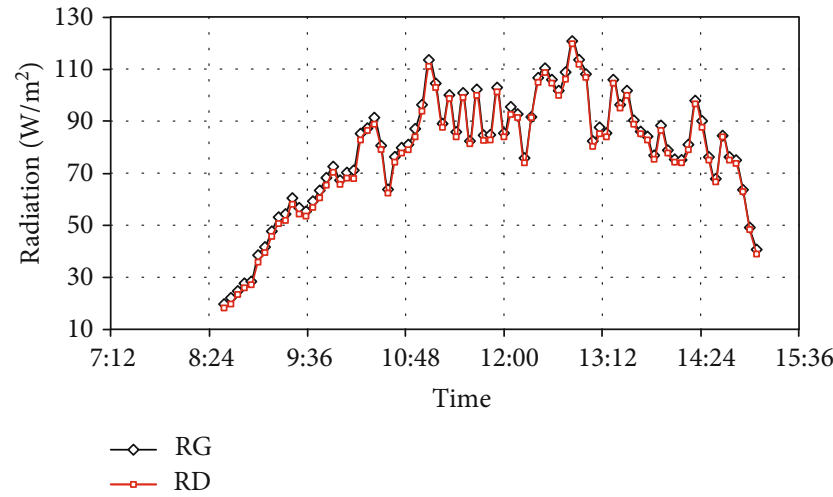

(b)

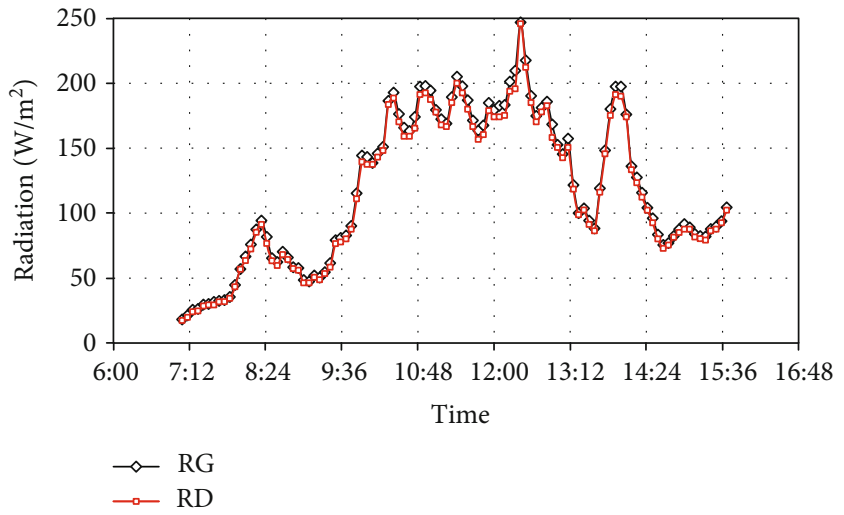

(d)

FIGURE 6: The solar global (RG) and diffuse radiation (RD): (a) winter clear day, (b) winter cloudy day, (c) summer clear day, and (d) summer cloudy day.

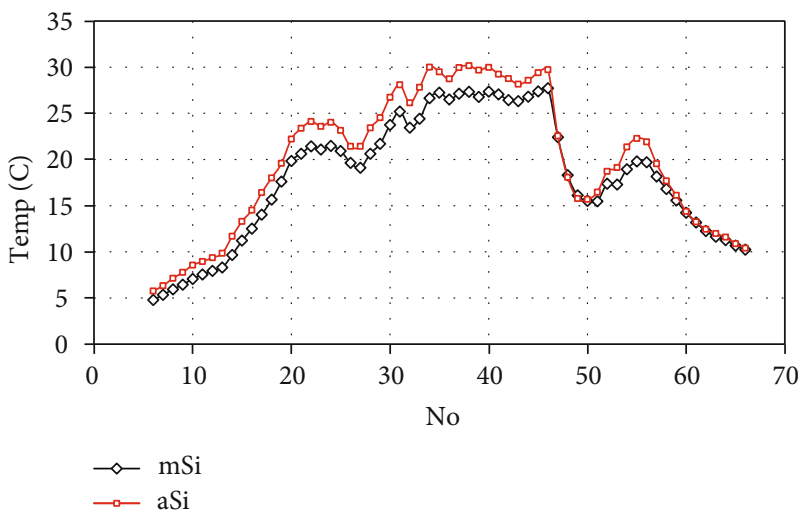

(a)

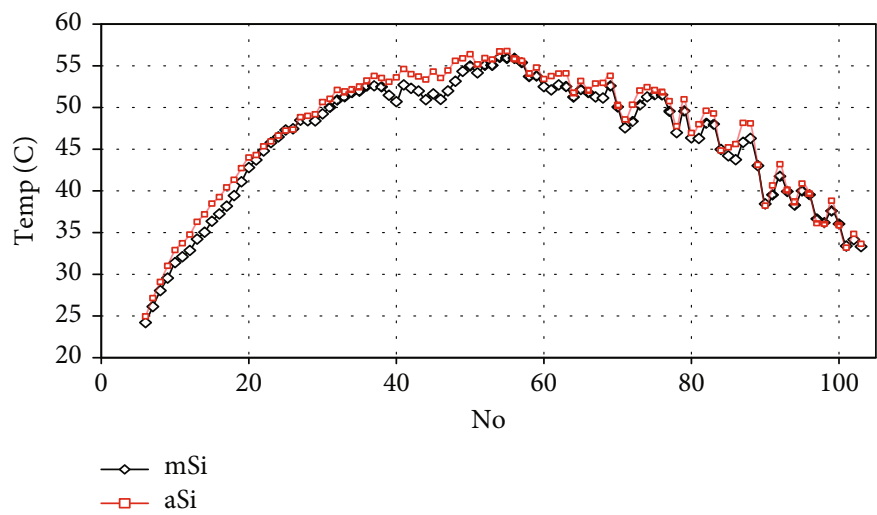

(b)

FIgURE 7: The temperature of the two photovoltaic panels: (a) winter day and (b) summer day.

photovoltaic panels, $0.87 \% /$ year for the amorphous silicon photovoltaic panels manufactured after 2000, 0.47\%/year for the monocrystalline silicon panel, and $0.96 \%$ for the aSi panels manufactured before 2000 [38]. For the photovoltaic panels manufactured after 2000, the median degradation rate decreases with $10 \%$ for the aSi panels and with $20 \%$ for the monocrystalline silicon panels compared to that for panels manufactured before 2000 .
The degradation rate is influenced by climate conditions, geographical relief, and so on. Therefore, it is important to study the lifetime behaviour of the PV panels for particular conditions. After two years, the degradation rate of the monocrystalline silicon panel is $1.02 \%$, and for the aSi panel, it is $1.97 \%$ for this study. The monocrystalline silicon panel has an advantage on the long term because the degradation rate is almost two times smaller than that for the aSi panel. 
TABLE 2: Mean efficiency for the two photovoltaic panels.

\begin{tabular}{lcc}
\hline \multirow{2}{*}{ Irradiance $\left(\mathrm{W} / \mathrm{m}^{2}\right)$} & \multicolumn{2}{c}{ Average efficiency $(\%)$} \\
& $\mathrm{mSi}$ & $\mathrm{aSi}$ \\
\hline 100 & 10.66 & 4.45 \\
1000 & 8.34 & 3.48 \\
\hline
\end{tabular}

The aSi photovoltaic panel has a lower cost than the monocrystalline silicon panel, but the difference is not significant. The medium price for the aSi panel is $0.84 \$ / \mathrm{W}$, while for $\mathrm{mSi}$ it is $1.1 \$ / \mathrm{W}$ [19]. The lowest price is $0.69 \$ / \mathrm{W}$ for $\mathrm{aSi}$ and $0.75 \$ / \mathrm{W}$ for $\mathrm{mSi}[39]$. The lower price for the aSi photovoltaic panel is an advantage, but in addition to this price, the supplementary cost for the mounting must also be taken into consideration because for the same power an almost double area is needed.

The price for the two photovoltaic panels used, which are commercial panels, is almost the same with the lowest price. The common solar garden lamps use PV panels with a very small area because the required energy is very low, and consequently, the cost becomes a secondary aspect. It can be important for smart solar garden lamps, such as XSolar L-S [40], for whose prototype the authors contributed, where the necessary energy is in the order of watts.

\section{Conclusions}

The performance analysis for two commercial photovoltaic panels, monocrystalline and amorphous silicon, with small sizes $10 \mathrm{~cm} \times 10 \mathrm{~cm}$, was performed and presented. The experimental setup to measure the $I-V$ characteristics of the two photovoltaic panels, the solar global radiation, and the temperature of the PV panels and the software for data processing were developed.

The maximum power of the PV panels is the parameter taken into account to achieve the comparison because the area of the PV panels is the same. Firstly, the maximum power generated by the two photovoltaic panels and the normalized power are measured for tilts between $0^{\circ}$ and $90^{\circ}$ on the N-S direction in order to have an initial image of their behaviour. Then, the panels were tilted at $55^{\circ}$ which is the optimum angle for the critical period in the case of the solar garden lamps. The $I-V$ characteristics of the two panels are measured during two years and are used to determine the maximum power of them. Also, the temperature of the two panels is measured during the test period. Comparing the average maximum power generated by the two panels shows that the average maximum power of the monocrystalline silicon panel is over two times higher than the one generated by the amorphous silicon panel. This value increases to almost three on clear winter days due to the temperature decrease of the monocrystalline silicon panel. The gain is over 1.9 times even for very low irradiance, under $100 \mathrm{~W} / \mathrm{m}^{2}$. The difference in temperature between the amorphous silicon panel and the monocrystalline silicon panel is higher in winter days than in summer days. It is positive during the measurement period. Therefore, the monocrystalline silicon panel is space efficient, analyzing the maximum power generated by the two photovoltaic panels.
The median degradation rate is another advantage for the panel which is almost two times lower than the one for aSi. The cost and the maximum power temperature coefficient are lower for the aSi photovoltaic panel which can be an advantage. However, the cost of the aSi system increases because it is necessary to double the area to obtain the same power generated as in the monocrystalline Si case.

Taking into consideration these aspects, the monocrystalline silicon panel is the most suitable for the applications with limited space, such as smart and common solar garden light.

The behaviour of the parameters, such as the short circuit current, the reverse saturation current, the ideality factor of diode, the series resistance, and the shunt resistance, for the two photovoltaic panels will be analyzed in the future work using the $I-V$ characteristics and different parameter extraction methods.

\section{Data Availability}

Some of the data used in this work are available in Annex and the rest can be provided upon request from authors (email addressesdtcotfas@unitbv.ro and pcotfas@unitbv.ro).

\section{Disclosure}

A first version of the paper was presented at the international conference for Alternative Energy Sources, Materials and Technologies (AESMT'18), Plovdiv, Bulgaria.

\section{Conflicts of Interest}

The authors are employed at Transilvania University of Brasov.

\section{Supplementary Materials}

Annex: the maximum power and the normalized power for the two monocrystalline and amorphous photovoltaic panels measured in function of the tilt angles are given. Also, the average maximum power of the monocrystalline and amorphous photovoltaic panels is calculated for different values of the irradiance which varies from $100 \mathrm{~W} / \mathrm{m}^{2}$ to $1000 \mathrm{~W} / \mathrm{m}^{2}$, the two panels being tilted at $55^{\circ}$. The maximum power for different tilt angles (monocrystalline and amorphous panels). (Supplementary Materials)

\section{References}

[1] Next generation solar cells, The Future of Renewable Energyhttp://mnre.gov.in.

[2] F. H. Alharbi and S. Kais, "Theoretical limits of photovoltaics efficiency and possible improvements by intuitive approaches learned from photosynthesis and quantum coherence," Renewable and Sustainable Energy Reviews, vol. 43, pp. 1073-1089, 2015.

[3] M. A. Green, Y. Hishikawa, E. D. Dunlop, D. H. Levi, J. HohlEbinger, and A. W. Y. Ho-Baillie, "Solar cell efficiency tables (version 52)," Progress in Photovoltaics: Research and Applications, vol. 26, no. 7, pp. 427-436, 2018. 
[4] D. M. Bagnal and M. Boreland, "Photovoltaic technologies," Energy Policy, vol. 36, no. 12, pp. 4390-4396, 2008.

[5] K. D. G. I. Jayawardena, L. J. Rozanski, C. A. Mills, M. J. Beliatis, N. A. Nismya, and S. R. P. Silva, "Inorganics-in-organics': recent developments and outlook for $4 \mathrm{G}$ polymer solar cells," Nanoscale, vol. 5, no. 18, pp. 8411-8427, 2013.

[6] A. J. Carr and T. L. Pryor, "A comparison of the performance of different PV module types in temperate climates," Solar Energy, vol. 76, no. 1-3, pp. 285-294, 2004.

[7] M. A. Bashir, H. M. Ali, S. Khalil, M. Ali, and A. M. Siddiqui, "Comparison of performance measurements of photovoltaic modules during winter months in Taxila, Pakistan," International Journal of Photoenergy, vol. 2014, Article ID 898414, 8 pages, 2014.

[8] A. Dolara, S. Leva, and G. Manzolini, "Comparison of different physical models for PV power output prediction," Solar Energy, vol. 119, pp. 83-99, 2015.

[9] N. Amin, C. W. Lung, and K. Sopian, "A practical field study of various solar cells on their performance in Malaysia," Renewable Energy, vol. 34, no. 8, pp. 1939-1946, 2009.

[10] M. Sadok and A. Mehdaoui, "Outdoor testing of photovoltaic arrays in the Saharan region," Renewable Energy, vol. 33, no. 12, pp. 2516-2524, 2008.

[11] M. Ohmukai and A. Tsuyoshi, "Comparison between amorphous and tandem silicon solar cells in practical use," Journal of Power and Energy Engineering, vol. 05, no. 04, pp. 9-14, 2017.

[12] C. Canete, J. Carretero, and M. Sidrach-de-Cardona, "Energy performance of different photovoltaic module technologies under outdoor conditions," Energy, vol. 65, pp. 295-302, 2014.

[13] I. Visa, B. Burduhos, M. Neagoe, M. Moldovan, and A. Duta, "Comparative analysis of the infield response of five types of photovoltaic modules," Renewable Energy, vol. 95, pp. 178190, 2016.

[14] C. L. A. Dias, D. A. C. Branco, M. C. Arouca, and L. F. L. Legey, "Performance estimation of photovoltaic technologies in Brazil," Renewable Energy, vol. 114, pp. 367-375, 2017.

[15] O. M. Midtgard, T. O. Sætre, G. Yordanov, A. G. Imenes, and C. L. Nge, "A qualitative examination of performance and energy yield of photovoltaic modules in southern Norway," Renewable Energy, vol. 35, no. 6, pp. 1266-1274, 2010.

[16] M. R. Abdelkader, A. Al-Salaymeh, Z. Al-Hamamre, and F. Sharaf, "A comparative analysis of the performance of monocrystalline and multiycrystalline PV cells in semi-arid climate conditions: the case of Jordan," Jordan Journal of Mechanical and Industrial Engineering, vol. 4, pp. 543-552, 2010.

[17] M. Ito, M. Kudo, M. Nagura, and K. Kurokawa, “A comparative study on life-cycle analysis of 20 different pv modules installed at a Hokuto mega-solar plant," in 25th European Photovoltaic Solar Energy Conference and Exhibition/5th World Conference on Photovoltaic Energy Conversion, Valencia, Spain, January 2011.

[18] A. Bianchini, M. Gambuti, M. Pellegrini, and C. Saccani, "Performance analysis and economic assessment of different photovoltaic technologies based on experimental measurements," Renewable Energy, vol. 85, pp. 1-11, 2016.

[19] A. A. Hossam El-din, C. F. Gabra, and A. H. H. Ali, "A comparative analysis between the performances of monocrystalline, polycrystalline and amorphous thin film in different temperatures at different locations in Egypt," in 1 st Africa
Photovoltaic Solar Energy Conference and Exhibition, Durban, March 2014.

[20] International Electrotechnical Commision (IEC), "International Standard IEC-61724: Photovoltaic System Performance Monitoring," Guidelines for Measurement, Data Exchange and Analysis, 1998.

[21] M. E. Başoğlu, A. Kazdaloğlu, T. Erfidan, M. Z. Bilgin, and B. Çakir, "Performance analyzes of different photovoltaic module technologies under İzmit, Kocaeli climatic conditions," Renewable and Sustainable Energy and Reviews, vol. 52, pp. 357-365, 2015.

[22] A. Balaska, A. Tahri, F. Tahri, and A. B. Stambouli, "Performance assessment of five different photovoltaic module technologies under outdoor conditions in Algeria," Renewable Energy, vol. 107, pp. 53-60, 2017.

[23] A. Abdallah, D. Martinez, B. Figgis, and O. El Daif, "Performance of silicon heterojunction photovoltaic modules in Qatar climatic conditions," Renewable Energy, vol. 97, pp. 860-865, 2016.

[24] D. A. Quansah and M. S. Adaramola, "Assessment of early degradation and performance loss in five co-located solar photovoltaic module technologies installed in Ghana using performance ratio time-series regression," Renewable Energy, vol. 131, pp. 900-910, 2019.

[25] T. A. Guerra, J. A. Guerra, B. O. Tabernero, and G. C. García, "Comparative energy performance analysis of six primary photovoltaic technologies in Madrid (Spain)," Energies, vol. 10, no. 6, p. 772, 2017.

[26] V. Komoni, A. Gebremedhin, and N. Ibrahimi, “A comparison of the performance of mono-Si and poly-Si photovoltaic modules operating under Kosovo climate condition," Journal of Renewable and Sustainable Energy, vol. 10, no. 1, article 013504, 2018.

[27] E. Karami, M. Rafi, A. Haibaoui, A. Ridah, B. Hartiti, and P. Thevenin, "Performance analysis and comparison of different photovoltaic modules technologies under different climatic conditions in Casablanca," Journal of Fundamentals of Renewable Energy and Applications, vol. 07, no. 03, pp. 1-6, 2017.

[28] N. M. Kumar, K. Sudhakar, and M. Samykano, "Performance comparison of BAPV and BIPV systems with c-Si, CIS and CdTe photovoltaic technologies under tropical weather conditions," Case Studies in Thermal Engineering, vol. 13, article 100374, 2019.

[29] A. Ameur, A. Sekkat, K. Loudiyi, and M. Aggour, "Performance evaluation of different photovoltaic technologies in the region of Ifrane, Morocco," Energy for Sustainable Development, vol. 52, pp. 96-103, 2019.

[30] P. J. Ribeyron, "Crystalline silicon solar cells: better than ever," Nature Energy, vol. 2, no. 5, article 17067, 2017.

[31] "Amorphous silicon will continue to dominate thin-film PV market," November 2018, http://www.renewableenergyfocus .com/view/1131/amorphous-silicon-will-continue-todominate-thin-film-pv-market/.

[32] Fraunhofer ISE, Photovoltaics Report, Fraunhofer ISE, Freiburg, 2014, November 2018, http://www.ise.fraunhofer.de.

[33] D. T. Cotfas and P. A. Cotfas, "PV innovative techniques and experimental test sets," in Renewable Energy Systems: Theory, Innovations and Intelligent Applications, S. Kaplanis and E. Kaplani, Eds., pp. 525-546, Nova Science Publishers, USA, 2013. 
[34] D. T. Cotfas, P. A. Cotfas, and S. Kaplanis, "Methods to determine the dc parameters of solar cells: a critical review," Renewable and Sustainable Energy Reviews, vol. 28, pp. 588-596, 2013.

[35] November 2018, http://re.jrc.ec.europa.eu/pvgis/apps4/pvest .php.

[36] D. T. Cotfas, P. A. Cotfas, and O. M. Machidon, "Study of temperature coefficients for parameters of photovoltaic cells," International Journal of Photoenergy, vol. 2018, Article ID 5945602, 12 pages, 2018.

[37] X. Song, E. L. Miller, and D. Garmire, Experimental study of solar spectrum impact on solar cells, Technical Proceedings of the 2010 Clean Technology Conference and Trade Show, University of Hawaii at Manoa, US, 2010.

[38] D. C. Jordan and S. R. Kurtz, "Photovoltaic Degradation Rates-an Analytical Review," Progress in Photovoltaics Research and Applications, vol. 21, no. 1, pp. 12-29, 2013.

[39] V. Alfonsohttp://www.josre.org/wp-content/uploads/2012/10/ Photovoltaics-Choices-Costs-and-Benefits-by-Victor-Alfonso .pdf.

[40] April 2019, https://www.steinel.de/en/lights-floodlights/solarlights/xsolar-1-s-silver.html. 

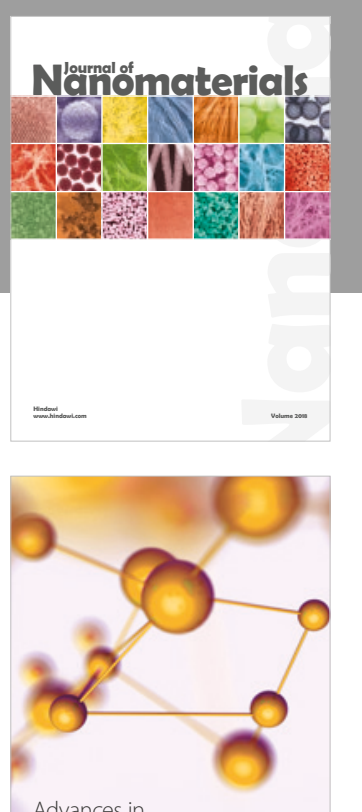

Physical Chemistry
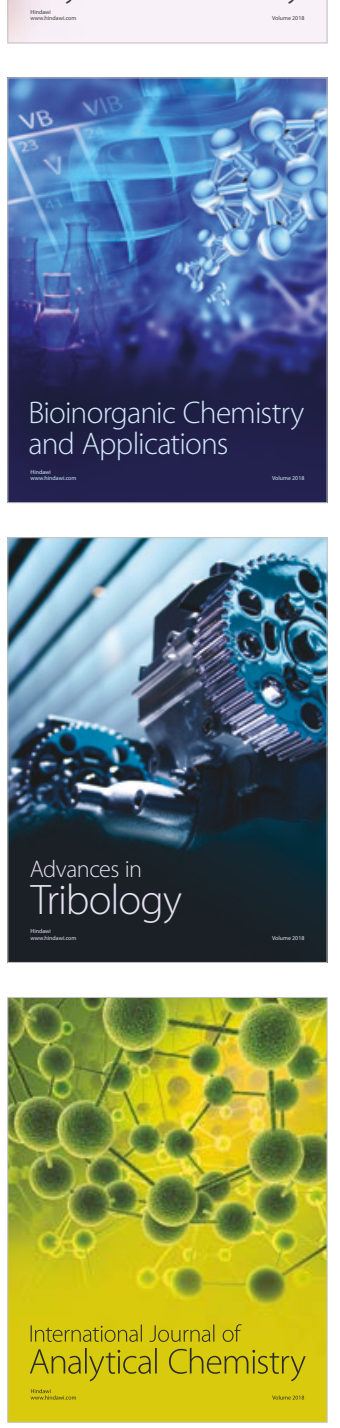

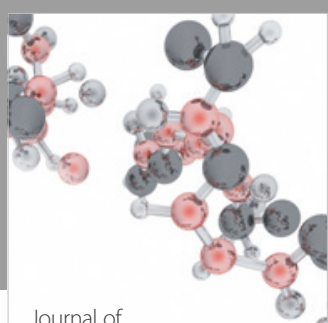

Analytical Methods

in Chemistry

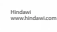

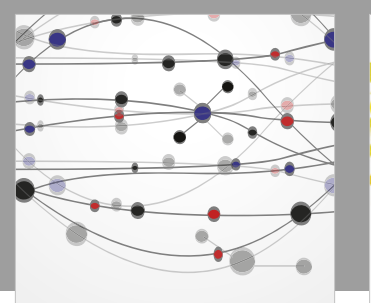

The Scientific World Journal

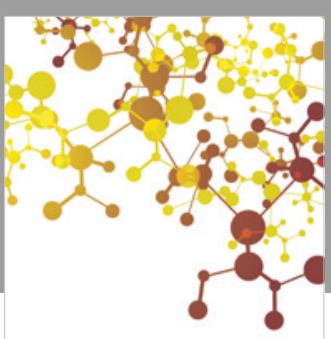

Journal of

Applied Chemistry
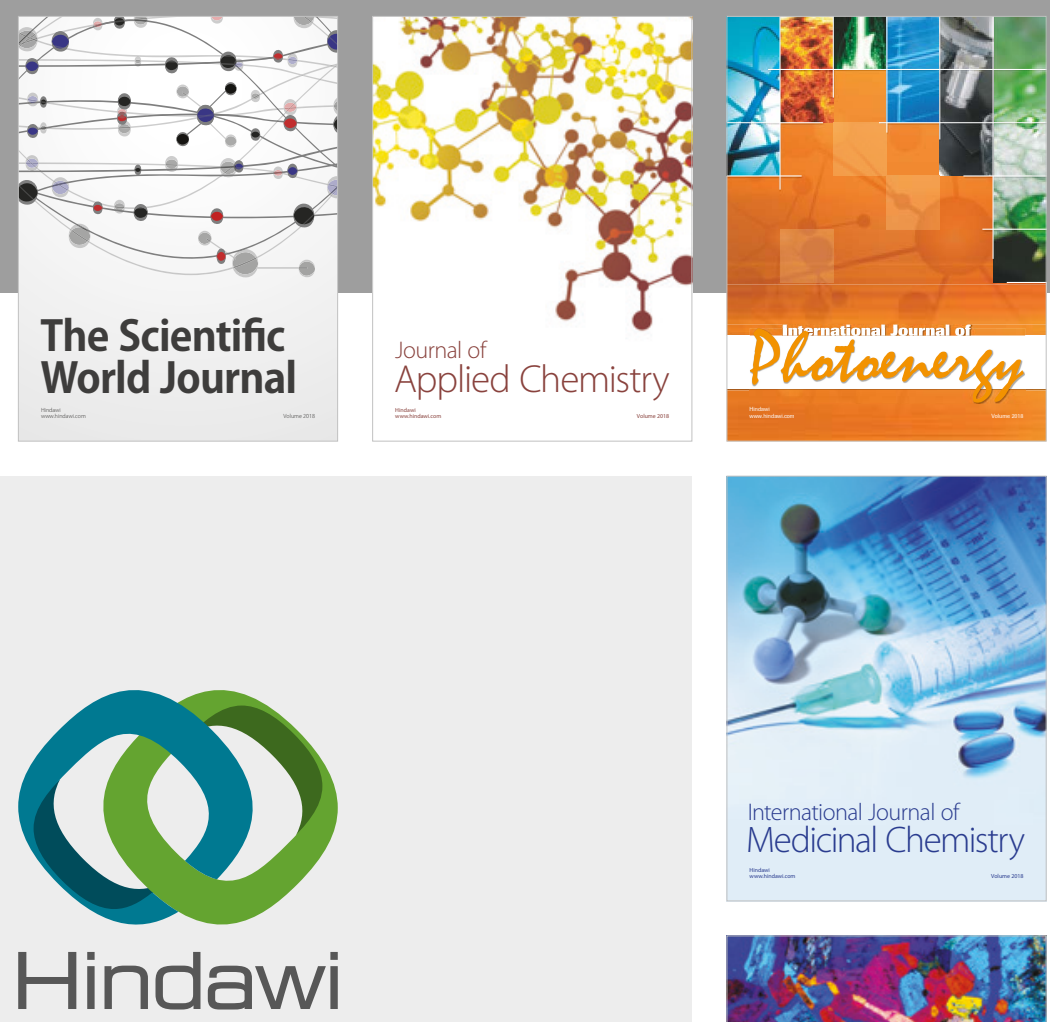

Submit your manuscripts at

www.hindawi.com
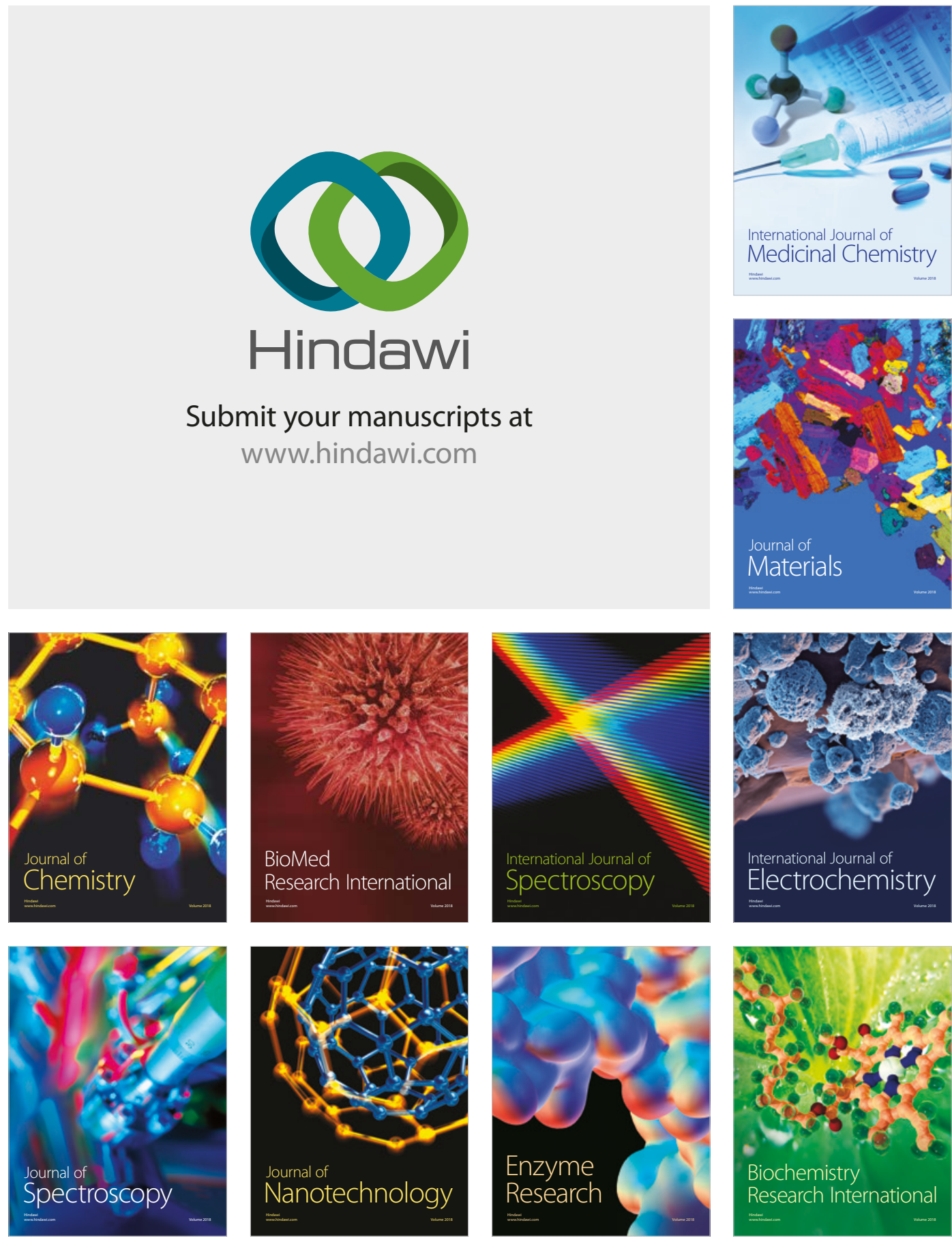
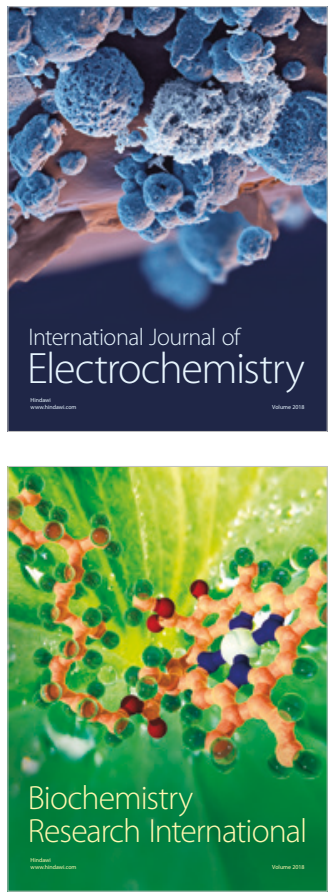